0

\title{
Renewable energy fueled desalination in Israel
}

\author{
W. Meindertsma ${ }^{\mathrm{a}, \mathrm{b}}$, W.G.J.H.M. van Sark ${ }^{\mathrm{a} *}$, C. Lipchin ${ }^{\mathrm{b}}$ \\ ${ }^{a}$ Science, Technology and Society, Copernicus Institute for Sustainable Development and Innovation, Utrecht University, Heidelberglaan \\ 2, 3584 CS Utrecht, the Netherlands \\ Tel. +31 30 2537611; Fax +31 30 2537601; email: w.g.j.h.m.vansark@uu.nl \\ ${ }^{b}$ Arava Institute for Environmental Studies, Kibbutz Ketura D.N. Hevel Eilot 88840, Israel
}

Received 20 August 2009; accepted 2 November 2009

\section{A B S T R A C T}

The projected negative effects of climate change on the global water distribution and a steady rise in demand have made water scarcity a prominent topic on political agendas. Confronted with the prospect of increasingly severe water shortages, many governments turn to desalination as the panacea for their problems. This is particularly true for Israel, which is currently exploiting most of its available renewable water resources and has been confronted with severe droughts during the past years. Conventional desalination, however, is based on fossil fuels, causing it to be inherently unsustainable. Desalination based on renewable energy can prove to be a viable alternative to conventional desalination. This article evaluates the feasibility of large-scale renewable energy desalination plants in Israel. In doing so, it examines the economical and environmental aspects of large-scale renewable energy desalination plants and analyses the water market in Israel. In the long run, the disadvantages of fossil fuels and the benefits of renewable energy for the Israeli economy advocate the rapid introduction of renewable energy for desalination and other uses. The most promising form of renewable energy in Israel is concentrating solar power. Recommendations and suggestions on how to facilitate the introduction of concentrating solar power are presented in the end of this article.

Keywords: Desalination; Seawater; Renewable energy; Large scale; Economic analysis; Israel

\section{Introduction}

During the last decades, water scarcity has become a prominent problem in Israel, Jordan and the Palestinian Authorities alike. The current water shortage is expected to become progressively worse in the following decades due to population growth, overexploitation of renewable water resources and the effects of climate change [1].

A common method of reducing water scarcity in the Middle East is by increasing the water supply through

${ }^{*}$ Corresponding author the construction of brackish or seawater desalination plants. In the last decade, Israel has constructed several large-scale fossil fuel powered desalination plants with a total capacity of 130 million cubic meter (million $\mathrm{m}^{3}$ ) per year. Total projected water demand for Israel in 2010 is 2,405 million $\mathrm{m}^{3}$ annually [2]. The use of conventional desalination plants, however, has several disadvantages; the finite nature of fossil fuels, the contribution of fossil fuels to the greenhouse gas effect and the dependency on fossil fuels imported from foreign countries; the latter being important for Israel, because of the volatile political situation of the Middle East. Desalination powered by renewable energy does not have these problems. 
Recent increases in the prices for fossil fuels have rekindled the interest in renewable energy fueled desalination. Due to the increased level of maturity of both technologies, their combined introduction in the water market has become more promising in the last couple of years. Israel in particular is a suitable location for the development of renewable energy fueled desalination due to the high level of experience in water management, the availability of technical knowledge and the increasing need for additional water resources.

This article evaluates the economical and technological feasibility of renewable energy fueled desalination on a large scale in Israel. This is done by evaluating the potential of desalination in the Israeli water market, creating an overview of renewable energy in Israel and investigating the economic parameters associated with the two. By combining the results, it can be determined whether or not the introduction of large-scale renewable energy fueled desalination plants is feasible.

\section{Desalination as a solution - Israel's water policy}

Israel is relying mainly on seawater desalination to combat the continuing water shortages that have reoccurred during the last years. The concept of desalination, however, is not new in Israel. An increased role of desalination in the Israeli water market has been discussed since the late 1950s. Around that time, desalination was mainly used to provide water to remote regions of the country, which were not connected to the National Water Carrier (NWC). The NWC is responsible for the transfer of water from the water rich northern regions of Israel to large population centers in the south of the country. Desalination plants were relatively small and the main feed water of desalination plants was brackish water instead of seawater. Desalination on a large scale was put off by water conservation measures, expanding the NWC, the more efficient use of water in agriculture and an increased recycling of wastewater [2].

During the 1990s, Israel suffered from a prolonged series of droughts. As a consequence, water reserves dwindled rapidly and abrupt reductions in water allocation were inevitable. Around the same time, studies revealed that the continued overexploitation of natural water resources caused the quality of these water resources to deteriorate. It was expected that if overexploitation persisted, these water resources were in danger of becoming unusable altogether [3]. Water demand has increased during the last decades and this trend is expected to persist, due to a continued population growth and increases in living standards. In order
Table 1

Sectoral breakdown of water demand development in million $\mathrm{m}^{3} /$ year [3]

\begin{tabular}{llll}
\hline Year & 2010 & 2015 & 2020 \\
\hline Agricultural & 1170 & 1270 & 1370 \\
Industrial & 135 & 148 & 155 \\
Domestic & 840 & 960 & 1080 \\
Nature conservation & 50 & 50 & 50 \\
Aquifer rehabilitation & 100 & 100 & 0 \\
Neighboring entities & 110 & 130 & 150 \\
Total demand & 2405 & 2658 & 2805 \\
\hline
\end{tabular}

to prevent natural water resources from deteriorating and to meet the increase in demand, the Israeli Water Commission (IWC), the official government agency dealing with national water resources, could no longer rely on its well-tried methods. Almost all natural water resources were being utilized and the use of fresh water in agriculture had reached the point where it could no longer be reduced [4]. A higher demand can only be accommodated through the use of treated wastewater, see Table 1.

The IWC commissioned an evaluation of the situation, which lead them to conclude that the problem was caused by defective water management. It believed that too much emphasis had been put on the development of existing water resources, neglecting research and development of new water resources [5]. The import of water from Turkey was briefly considered but did not come through because of economic and diplomatic considerations. This crisis coincided with a large decrease in seawater desalination costs due to large technological improvements. The IWC concluded that the introduction of seawater desalination on the Israeli water market could no longer be avoided and was necessary to combat the water shortage and alleviate the pressure on the natural water resources. It was convinced that the introduction of seawater desalination on a large scale was essential to guarantee the availability, reliability and quality of water in Israel [3].

In order to manage this change of the water market, the planning division of the IWC collaborated with ADAN Technical and Economic Services Ltd, a consultancy company from Tel Aviv, to compose a detailed plan which dealt with the issues of introducing desalination on a large scale in Israel. The resulting plan was dubbed the desalination master plan (DMP). The first version of the DMP was completed in 1997 and spanned a time span of 20 years. It included information on the most suitable location for desalination plants and which technologies to use. Even though the original DMP had to be revised and modified several 
times, over the years it lead to the successful introduction of several large desalination plants in Israel.

The IWC believes that Israel presently is using all its land-based available renewable water resources to the fullest extent. Furthermore, the IWC claims that in order to guarantee the reliability of the water supply in Israel on the long term, it has to rehabilitate the aquifers that have been overexploited during the last decades. They have allocated 100-200 million $\mathrm{m}^{3}$ of water yearly for this purpose [3]. The only short term economically feasible solution to maintain a reliable water supply in Israel is to increase the seawater desalination capacity.

In order to guarantee a reliable supply of affordable water for its citizens, Israel has to expand its desalination capacity. Although desalinated water is expensive compared to conventional water sources, it is economical compared to other alternatives. Even though the environmental effects of conventional desalination are considerable, Israel currently has no other option for the expansion of its water supply. Israel would do best to increase its overall energy capacity for desalination through the development of renewable energy. The use of renewable energy for desalination has the potential to mitigate many of the negative effects of conventional desalination. The use of renewable energy guarantees a reliable supply of affordable water. Because in desalination water prices are directly linked to energy prices, the fluctuation of the prices of fossil fuel derived energy is reflected in the price of water. By relying solely on fossil fuels, the price of water can drastically escalate due to turmoil in the Middle East and fluctuating energy prices [6]. Furthermore, the use of renewable energy reduces the environmental consequences of desalination and health related issues.

This article is organized as follows. Section 3 focuses on the costs and benefits of desalination. It details present direct, indirect, and environmental costs. A brief overview of the status of renewable energy in Israel is presented in Section 4. Subsequently, current desalination plants and future plans are described in Section 5, and in Section 6 it will be argued that solar powered desalination is the only viable option for Israel to enlarge its desalination capacity. In Sections 7 and 8 recommendations are given, and conclusions drawn, respectively.

\section{Costs and benefits of desalination}

\subsection{The cost of desalination}

The prices of desalinated water in Israel are low compared to the prices of desalinated water in other countries. According to Hoffman et al. [4], operation costs for desalination plants in Israel are lower than those of any other seawater desalination plant in the world, despite Israel's relatively high energy costs. Karagiannis and Soldatos [7] state that the costs for seawater desalination plants with a capacity larger than 22 million $\mathrm{m}^{3} / \mathrm{yr}$ lie between 0.50 and 1.00 US\$ per cubic meter $\left(\mathrm{m}^{3}\right)$. The difference in prices is due to the large amount of factors involved, such as plant reliability, concentrate disposal and product water quality [8]. Dreizin [3] claims that the costs of seawater desalination in Israel range from 0.50 to $0.60 \mathrm{US} \$$ per $\mathrm{m}^{3}$, supporting the claim made by Hoffman and placing desalination costs in Israel among the lowest costs worldwide.

Dreizin and Israeli provide several reasons for the low desalination costs in Israel [3,9]:

- State-of-the-art technology, resulting in lower specific energy consumption and decreased capital costs. The Ashkelon plant has an energy recovery rating of around $25 \%$, which compares favorable to other desalination plants [10].

- Favorable financial agreements, providing loans with low interest rates.

- Long purchase periods of the construction and operation agreements between the Israeli government and the involved parties and a contract securing natural gas at a very favorable price for the next 25 years.

- Gains through the effect of economies of scale.

Dreizin illustrates the last point as follows: because Israel has an efficient national water distribution system, it is not necessary to supply remote regions with small-scale local desalination plants. This means that a small number of large desalination plants are able to supply the entire country with fresh water. Large desalination plants are more practical in economical terms since they enjoy the benefits of economies of scale, thereby reducing the costs of water [2].

When comparing the costs of desalination in Israel with the recent costs of similar scale seawater reverse osmosis (SWRO) desalination plants worldwide, it appears that costs are average. Karagiannis and Soldatos [7] summarized the cost of desalinated seawater for reverse osmosis ( $\mathrm{RO}$ ) plants with a capacity between 37 and 117 million $\mathrm{m}^{3} / \mathrm{yr}$ as mentioned in the literature to be in the range of 0.45 to 0.66 US $\$$ per $\mathrm{m}^{3}$.

The most recent data available on the costs of desalination in Israel is provided by Dreizin et al. [2] in Table 2. His data from December 2006 indicates the following costs for desalinated water from the Hadera, Palmachim and the Ashkelon plants.

The contracted price for desalinated water at the Ashkelon plant at the end of 2001 was 0.525 US\$ per $\mathrm{m}^{3}$ [4]. 
Table 2

Costs of water [3]

\begin{tabular}{llll}
\hline Desalination plant & Ashkelon & Palmachim & Hadera \\
\hline Total costs (2006 US\$/m3) & 0.66 & 0.74 & 0.61 \\
\hline
\end{tabular}

The discrepancy between this price and the prices presented in Table 2 is largely due to the increases in energy costs over the last couple of years. The prices of desalinated water in Israel are linked to three cost escalation indexes; the electricity price, the average Israeli consumer price index (CPI) and the exchange rate of the dollar and the Israeli national currency (shekel). This implies that the price of desalinated water fluctuates in accordance to these indexes [3]. Zhou and Tol demonstrate in a sensitivity analysis the large effect of fossil fuel prices on desalination costs [11]. This indicates the important correlation between energy prices and water prices.

Compared with other sources of water in Israel, prices for desalinated water are high. Table 3 presents the cost of water in Israel according to source. The costs include transport and treatment costs and are indicative for the costs associated with the delivery of potable water to the end user, either for agricultural or industrial purposes or to urban population centers.

The data from Table 3 might give the impression that there are many cheap alternatives to seawater desalination. However, when looking to expand the water supply, the water sources, which are already exploited to their fullest extent, should not be taken into consideration. Only those water resources that have the potential to increase their output in the future, which are few, are of importance. The main alternative to seawater desalination is the desalination of municipal wastewater. Besides the psychological issues associated with the re-use of municipal wastewater, it appears that its costs are in the same range as that of desalinated seawater [3]. One can argue that in the

Table 3

Water costs in Israel according to source [3]

\begin{tabular}{ll}
\hline Source & $\begin{array}{l}\text { Costs } \\
\left(2006 \mathrm{US} \$ / \mathrm{m}^{3}\right)\end{array}$ \\
\hline Sea of Galilee water via the National Carrier & $0.37-0.45$ \\
Mountain aquifer water & $0.30-0.40$ \\
Coastal aquifer water & $0.15-0.25$ \\
Brackish well water & $0.15-0.25$ \\
Desalinated brackish water & $0.40-0.60$ \\
Conventionally treated wastewater & $0.35-0.45$ \\
Desalinated wastewater & $0.50-0.60$ \\
\hline
\end{tabular}

nearby future, the costs of desalinated water are going to increase compared to water from other sources due to the predicted increase in energy prices [3]. While this observation is correct, prices for alternative sources of water are also expected to increase, due to increasing marginal costs, the overexploitation of existing water resources and more stringent quality standards, thereby not reducing the competitiveness of desalination [8].

\subsection{Indirect costs and benefits of desalination}

The introduction of desalinated seawater into the water distribution network of Israel is accompanied by a number of indirect costs and benefits that influence the economics of desalinated water. These effects should be taken into account when determining the economical potential of desalination as an alternative water resource.

Desalination has several advantages that yield indirect economical benefits. First of all, the introduction of desalinated water to the Israeli water supply improves the quality of the water. By blending the high quality water from the desalination plants with the lower quality water from conventional water resources, the hardness and the nitrate levels of the water decrease. This has numerous positive effects, such as the increased lifetimes of electric and solar water heaters, a decrease in the use of water treatment and less water usage for rinsing salt from crops. The second benefit of desalinated water lies in the energy saved on pumping. Less pumping is necessary because the water from the desalination plant is supplied closer to densely populated areas and thus less water has to be pumped from the north of the country. Finally, the reliability of the water supply is improved. This diminishes the need to drastically reduce water allotments during drought spells, preventing the loss of crops due to a lack of water [3]. Also, the total economic gain attributed to the introduction of desalinated seawater to the national water carrier amounts to 0.152 US\$ per $\mathrm{m}^{3}$ [3]. Because most advantages are site specific and differ according to circumstances, the total economic gain is an average.

The introduction of desalinated water in Israel's water supply is also accompanied by indirect costs. The government faces additional costs that arise from the construction of the desalination plant and its introduction to the NWC. The most important costs are the administration costs associated with the issuing of the tender and the construction of additional infrastructure to accompany the increase of the bulk of water to be transported. Besides these initial costs, the government 
also has to reserve funds for the annual operation and maintenance of the infrastructure, including costs associated with the supervision and the administration of the process. The third factor is the costs associated with the risks involved in the construction and operation of the desalination plant. These risks consist of, but are not limited to, natural disasters of a large magnitude, terrorist attacks or the outbreak of hostilities or war. No matter how small the chances are they would ever occur, the government has to prepare itself for these events. It can do so by setting aside a reserve of money as an insurance policy. Altogether, the conjunction of these cost factors increases the price of desalination by about 0.089 US $\$$ per $\mathrm{m}^{3}$ [3].

Taking into account the indirect costs of desalinated water in the Israeli water market gives an indication of the actual price of desalinated water for the government. Even though the economical benefits of desalination are important when considering desalination as a proper solution to the water shortage in Israel, caution should be used when using them to offset its high costs, because the benefits apply to society as a whole and do not reduce the price of desalination for the government as such. Furthermore, desalination is also responsible for negative externalities to society. The next chapter will evaluate the effects of desalination on the environment.

\subsection{The environmental effect of fossil fueled seawater desalination}

In order to determine whether seawater desalination is a proper solution for the water shortage in Israel, its effects on the environment have to be considered. Costs resulting from effects on the environment are important to determine the economical potential of desalination. There have been many studies on the effects of desalination on the environment, although there is little information on the effects of large scale seawater desalination on the long term due to its large recent surge in capacity. Environmental effects that apply to any large scale construction project, such as land use and noise pollution, are not specific for desalination plants and have not been included in this analysis.

The most controversial environmental issue of seawater desalination is the effect of the water intake and the reject stream on the marine environment. The intake of large volumes of seawater has an adverse effect on aquatic organisms. The construction of intake mechanisms can harm the ocean floor and alter the ocean currents, which is detrimental for aquatic organisms. The reject stream of desalination plants can have a different temperature and chemical composition compared to the surrounding waters. The reject stream, or brine discharge, often contains pretreatment products and cleaning chemicals. The list of chemicals that can be found in the reject stream is diverse and different for each desalination plant. In their paper, Lattemann and Höpner [12] provide a comprehensive list of effluent properties for RO and thermal processes. For RO plants, which are predominately used in Israel, the temperature of the water is not affected, but chemical traces of chemicals against scale deposits, suspended solids and biofouling can be found [10]. For the effects of the reject stream of SWRO plants, Safrai and Zask [13] mention stratification, eutrophication and discoloration of the seawater. For more specific information, please refer to their detailed paper on the environmental effects of RO desalination plants. Even though there are some studies on the environmental impact of desalination plants in Israel, e.g. [13-15]. Safrai and Zask [13], Alon Tal [14] and Einav and Lokiec [15], there is still no empirical data available on what the effects of the reject stream of desalination are on the environment. With the surge in desalination capacity in the Arabian Gulf, the Red Sea and the Mediterranean, these effects could be amplified through the cumulative effects of the reject stream from multiple desalination plants [12].

Another major environmental problem associated with conventional desalination is the emission of air pollutants. As previously mentioned, using desalination is an energy intensive method of increasing the water supply. Because desalination is powered by energy derived from fossil fuels, such as oil, coal or natural gas, this large energy consumption coincides with high emissions of air pollutants. Air pollutants include sulfur dioxide, nitrogen oxides and several greenhouse gases. The addition of these gases to the atmosphere causes the phenomenon of global warming and climate change. Air pollutants also constitute a health hazard. The majority of large cities in the Middle East suffers from high levels of air pollution. Inhabitants of Jerusalem, Tel-Aviv and Gaza City are all exposed to pollution levels that are considered detrimental to public health according to international standards [6]. According to a study from 2003 conducted by the Ministry of Environment, the US EPA and the IUED, air pollution in Israel is responsible for more deaths than traffic accidents [16].

In their report for the IWC on large scale desalination in Israel, Dreizin et al. [2], ignore the previously mentioned environmental problems and claim that the main environmental concern regarding desalination is the high iron content of the brine discharge. The Ashkelon plant in particular has been a source of concern 
for the Israeli Ministry of Environmental Protection because it causes a discoloration of the sea, a phenomenon referred to as a "red plume", which is due to the high iron content of the brine discharge. The iron in the discharge is caused by the pretreatment of feed water with a coagulant named ferric sulfate. When it enters the plant, feed water is dosed with about 15 ppm of ferric sulfate. When it exits the plant as a discharge stream, it has a ferric sulfate content of about $28 \mathrm{ppm}$. The Ministry of Environment estimates the magnitude of the discharge to be around 450 tons per year [2]. According to Avraham Tenne, the Head of the Desalination Division for Mekorot Water Company this is not an important problem. He claims that research is being conducted on the effects of the increased iron content of seawater. If research indicates there are negative effects, a technology that is currently available can be put to use to stop the discharge. According to Tenne this will incur only minor additional costs for the desalination process.

Albeit maybe not a direct result from the actual desalination process, the use of desalination in Israel can also have positive effects for the environment. Since 1999 the IWC has initiated numerous initiatives to breech the gap between supply and demand of water resources in Israel. Among others, they have stimulated water conservation and promoted wastewater treatment. In spite of these efforts, potable water demand still exceeds the supply capacities of natural water resources by 250 million $\mathrm{m}^{3}$ annually. In order to avoid further cutbacks in water allotments and subsequent negative effects on the economy, more water is extracted from natural water resources per year than can be renewed, putting more strain on the already delicate water balance of the aquifers in Israel [2]. This results in the pollution of the aquifers, which renders them useless in the long run. By introducing more desalination plants to the water grid, the supply of renewable water resources is increased, alleviating pressure on the aquifers and allowing for their rehabilitation. Increasing desalination capacity is an effective method to allow the aquifers to recuperate from the overexploitation during the drought years, which is potentially essential for their continuity [12].

It is complex to give an accurate estimate of the environmental costs of desalination, because it is difficult to express climate change, damage to the marine environment and health hazards in economic terms. The fact that the environmental effects of the construction and operation of a large-scale desalination plant are different depending on the location and the type of desalination method used, makes the situation even more complicated. Desalination should be used with caution, integrated in water management plans and alternatives to desalination should be carefully examined. For Israel, desalination is the only option. In that case, it is important that the construction of every new desalination plant is accompanied by an Environmental Impact Assessment (EIA), in order to evaluate and minimize the negative effects of desalination plants on the environment [12].

\subsection{Energy requirements of desalination}

The main constituent of the O\&M costs of a desalination plant is the price of energy. The Foundation for Water Research estimates that for thermal seawater desalination processes, energy accounts for approximately $50 \%$ of the total desalination costs. For seawater reverse osmosis, this figure is slightly lower, on average around $44 \%$ [17]. According to statistics by Dreizin [3], the energy costs of the Ahskelon plant are responsible for $25.4 \%$ of the total water price. This is low compared to other desalination plants, because the SWRO in Ashkelon is using advanced energy recovery devices that reduce its specific energy consumption [10].

According to data by Al-Subaie from 2007, specific electricity consumption per cubic meter of desalinated water ranges from 2.0 to $5.0 \mathrm{kWh}$ per $\mathrm{m}^{3}$, depending on the nature of the desalination process. Al-Subaie distinguishes between the three most important desalination technologies, namely multi-stage flash (MSF), seawater reverse osmosis (SWRO) and multi-effect distillation (MED). Both MSF as well as MED also need a certain amount of thermal energy. Table 3 shows the specific average energy consumption for each technology [18].

Modern SWRO plants in Israel have a specific energy consumption that is generally lower than the figures indicated by Al-Subaie. This is due to the use of state of the art SWRO technologies which employ advanced energy recovery devices. Current and future desalination plants in Israel have an average specific energy consumption of less than $4 \mathrm{kWh}$ per $\mathrm{m}^{3}$ [2]. In [3] Dreizin mentions an even lower specific energy consumption, between 3 and $3.4 \mathrm{kWh}$ per $\mathrm{m}^{3}$. This figure is confirmed by Avraham Israeli, who mentions a specific energy consumption of $3.25 \mathrm{kWh}$ per $\mathrm{m}^{3}$ [9]. Alon Tal, however, estimates the average energy demand to be more around $3.85 \mathrm{kWh}$ per $\mathrm{m}^{3}$ [14]. The production of desalinated seawater consumes much more energy than the extraction of water from conventional sources in Israel, such as the lake of Galilee. The exploitation of water resources in Israel requires about 0.4 to $1.0 \mathrm{kWh}$ per $\mathrm{m}^{3}$ [3], depending on the source of the water and the location of the end user, see Table 4 . The majority of this energy is consumed for pumping water from water sources to water scarce regions. 
Table 4

Range of values for the specific energy consumption of the most prevalent desalination technologies and for SWRO and conventional water resources in Israel. Data is obtained from various publications on desalination and is valid for large scale seawater desalination facilities [8,19-21]

\begin{tabular}{lll}
\hline $\begin{array}{l}\text { Desalination } \\
\text { technology }\end{array}$ & $\begin{array}{l}\text { Electricity } \\
\text { consumption } \\
\left(\mathrm{kWh} / \mathrm{m}^{3}\right)\end{array}$ & $\begin{array}{l}\text { Thermal energy } \\
\text { consumption } \\
\left.\mathrm{MJ} / \mathrm{m}^{3}\right)\end{array}$ \\
\hline SWRO & $4.0-6.0$ & - \\
MSF & $2.5-4.0$ & $270-330$ \\
MED & $1.5-2.2$ & $120-260$ \\
SWRO in Israel & $3.0-3.4(3.85)$ & - \\
$\begin{array}{l}\text { Conventional } \\
\quad \text { water resources } \\
\text { in Israel }\end{array}$ & $0.4-1.0$ & - \\
\hline
\end{tabular}

The introduction of the Ahskelon plant to the National Water Carrier resulted in the saving of about 0.03 US\$ per $\mathrm{m}^{3}$ in energy pumping costs [3]; the energy costs of desalinating water in Ahskelon plant are 0.134 US\$ per $\mathrm{m}^{3}$ [3]. With a specific energy consumption of 3.2, the average of 3 and $3.4 \mathrm{kWh}$ per $\mathrm{m}^{3}$, this results in energy costs of 0.042 US\$ per $\mathrm{kWh}$. This implies that $0.7 \mathrm{kWh}$ per $\mathrm{m}^{3}$ was saved by introducing the Ashkelon plant to the NWC [3].

\section{Renewable energy in Israel}

\subsection{Overview of renewable energy in Israel}

The present energy economy in Israel is based primarily on imported fossil fuels, mainly consisting of crude oil and coal. Recently, natural gas has been introduced on the Israeli energy market. Israel has agreements with Egypt about the import of natural gas for a period of 15 years and natural gas reserves have been discovered in Israel's territorial waters. However, according to the Ministry of the Environmental Protection the energy economy of Israel is changing its focus to more sustainable and environmentally friendly energy sources [22]. Israel is a front-runner in the field of solar energy, a form of renewable energy that is very suitable for coupling with most conventional desalination processes. Flat solar collectors, solar ponds and parabolic troughs are some of the technologies that have been applied in Israel, albeit only on a small scale. The introduction of solar collectors for domestic heating has been very successful, being responsible for $3 \%$ of overall energy consumption.

Biogas, obtained from the digestion of organic components of waste in landfills, is expected to play a minor role in electricity and steam generation in Israel in the future. Due to the nature of biogas, it being a byproduct of a waste stream of which the quantity is hard to regulate, it does not qualify as a source of renewable energy suitable for desalination purposes. Wind energy resources in the Middle East are limited, and Israel has only two areas suitable for wind energy, both of them located far from the coast and in sparsely populated areas, making them unsuitable for large scale desalination purposes [23]. Israel has very little experience with wind energy and its operational wind power capacity in 2003 is $8 \mathrm{MW}$, a quantity dwarfed by its neighbor Egypt's capacity of $69 \mathrm{MW}$ [24]. Although a number of locations suitable for wind farms in Israel are possible, it is claimed that the most optimistic prognosis indicates no more than $200 \mathrm{MW}$ from wind energy [9].

Apart from the Dead Sea canal project, Israel lacks the geographical circumstances to develop hydropower. There are no substantial bodies of water that can be utilized to generate electricity [9] same is true for tidal energy, which is also not available to Israel [25].

Experience with geothermal energy in Israel is limited. In 1982, Koifman reported on the potential of geothermal resources, which showed promising results [26]. Findings indicated that useful geothermal sources could be tapped near Ashdod, Caesarea and north east of the Carmel range. He concluded that the exploitation of these resources for industrial purposes and space heating could have significant economical benefits [26]. However, Geothermal sources found in Israel tend to have a rather low capacity and a low temperature. Initially, geothermal activity in Israel was mainly applied in agriculture and for medical and recreational purposes. Energy from geothermal sources was used to provide hot water for greenhouses and spas. In the early 1990s, companies started to show interest in the use of hot, saline water in treatment resorts. Recently, the focus has shifted more towards the utilization of geothermal energy to supply low cost heat for fish ponds. Geothermal energy in Israel was not found suitable for large-scale electricity production and no geothermal energy plants were ever constructed [27]. Nevertheless, Israel uses a lot of geothermal energy compared to its land area. At the moment, geothermal fluids used in Israel amount to around 2,200 TJ annually [28]. According to international statistics, Israel ranks second on a world ranking list of TJ of geothermal energy used per area [29].

According to data from the Israel Export \& International Cooperation Institute, Israel has around 100 companies dealing with renewable energy. A number of these companies have experience with renewable energy on an international level and can provide the 
technologies necessary for renewable energy fueled desalination. The most important companies are Solel, LUZ II and E.D.I.G. Solar for solar-based renewable energy systems, Ormat Technologies, Inc. for geothermal power and IDE Technologies, Ltd. for desalination in general [30].

\subsection{Israel's sustainable energy policy}

According to a report by the Ministry of Environment from 2006, Israel has a sound sustainable energy policy, which includes the promotion of the use of natural gas, increasing the efficiency of energy systems and stimulating energy savings in different sectors of the economy. They also claim to promote the introduction of renewable energy sources [22]. Other organizations, such as the Israel Energy Forum and the "Paths to Sustainability Coalition" are less optimistic about Israel's sustainable energy policy.

The Ministry of Environment claims that Israel devotes efforts to research in solar energy but does not specify to what extent. They mention developments in flat solar collectors, parabolic troughs and solar ponds. Government regulations on the installation of solar collectors for water heating in new buildings in Israel have motivated $75 \%$ of households to use domestic solar heating [22]. Unfortunately, high costs have prevented the introduction of solar power plants on a large scale, despite the perfect geographical circumstances for solar energy and experience with solar energy abroad.

The Israel Energy Forum (IEF) is of a different opinion. The IEF is an organization dedicated to contribute to the implementation of a sustainable energy policy in Israel, in order to improve Israel's energy security and independence. They claim that Israel's energy sector is currently undergoing a crisis, characterized by frequent blackouts and additional emissions produced by coal fired power plants. At the same time they mention the increase in demand for energy caused by an increased desalination capacity and the effects of peak oil on energy prices in Israel, which mainly relies on imported fossil fuels. They mention that there is no clear national sustainable energy policy to deal with these issues [31].

The "Paths to Sustainability Coalition" is a group of 22 Israeli NGOs that work together to advocate sustainable development in Israel. They monitor the actions of the government and provide feedback to policy makers. In their position paper of April 2007 [32], they claim that in spite of promises made in 2003 to pursue national strategies for sustainable development, the government has not backed up their statements by a "real, coherent policy" nor by any "substantial actions to date". This is best illustrated by the 2007 budget, which allocates a mere amount of 0.5 million US\$ to the development of renewable energy, compared to annual fossil energy costs of 3.3 billion US\$. The Coalition is under the impression that the Israeli government is endorsing the polluting coal and oil economy and regards the emission of greenhouse gases and climate change as an irrelevance. In doing this, the government overlooks the real economic tag of the energy market and dismisses the real costs of air pollution. They claim that Israel has the potential to be a world leader in renewable energy technologies, if only the government would adjust its policy accordingly.

The fact that the energy sector in Israel is public and the lack of economic incentives does not stimulate the introduction of renewable energy to the energy market. Increased competition will allow small producers to sell clean energy to the grid. Economic incentives to use renewable energy, such as feed in tariffs, can lower the economical barrier for the introduction of renewable energy. A system of feed in tariffs similar to the one present in Germany, Italy and Spain, can help lower the economic barrier of renewable energy in Israel.

In the past there have been government decisions calling for the introduction of $2 \%$ electricity from renewable energy by 2007 and $5 \%$ by 2016 [22] Furthermore, in 2001, the Israeli Ministry of National Infrastructure announced its intentions to introduce Concentrating Solar Power (CSP) in the Israeli electricity market [33]. So far, however, nothing has happened, although recently tenders have been published to construct a solar power plant in the Negev (Avraham Israeli). The initial goal is a CSP plant of 100 MWe, which can later be expanded to 500 MWe.

\section{Overview of present and future desalination plants}

\subsection{The current situation of desalination in Israel}

There are currently 31 desalination plants operational in Israel, with a combined desalination capacity of 130 million $\mathrm{m}^{3}$ annually [34], which is a little over $9 \%$ of Israels national potable demand [2]. The majority of these plants are small-scale brackish water reverse osmosis plants (BWRO) that are used to supply water to remote regions in Israel and to treat brackish water for industrial and agricultural purposes. The largest BWRO plants producing potable water for the coastal city of Eilat are the Sabha A \& B plants, that have been operational since 1978 and 1992 [35]. Israel is also experimenting with wastewater desalination, but its application is up to now limited to small scale pilot plants [35]. 
Table 5

Overview of major desalination plants in Israel

\begin{tabular}{llll}
\hline Desalination plant & Type & Capacity (million $\left.\mathrm{m}^{3} / \mathrm{yr}\right)$ & Status \\
\hline Sabha A\&B Eilat & BWRO & 16 & Operational since 1978 and 1992 \\
Sabha C Eilat & SWRO & 4 & Operational since 1997 [36] \\
Ashkelon & SWRO & 100 & Operational since 2005 \\
Palmachim & SWRO & 30 & Operational since 2007 \\
\hline
\end{tabular}

The capacity of seawater desalination has increased rapidly in the last years. The oldest commercial seawater reverse osmosis (SWRO) plant is the Sabha C plant, located in Eilat. There are currently two large-scale SWRO plants operational in Israel. The largest one is located in Ashkelon and produces 100 million $\mathrm{m}^{3}$ of desalinated water per year. This makes it the largest RO desalination plant in the world. The second plant is located in Palmachim and is good for an annual production of 30 million $\mathrm{m}^{3}$ of desalinated water. An overview of the most important desalination plants in Israel can be found in Table 5.

\subsection{The future of desalination in Israel}

Priel et al. [37] advocate the use of marginal sources, such as brackish water and wastewater, for desalination on the basis of lower specific energy consumption and environmental considerations. They claim that in 10-20 years, the brackish water resources and wastewater available for desalination can amount to 500 million $\mathrm{m}^{3}$ annually. Although specific figures differ slightly, most studies agree that desalination brackish water is about half the price of desalination seawater $[7,14,37]$. By using these water resources for desalination instead of seawater, large amounts of energy and money can be saved [37]. In spite of the logic of this argument, Dreizin [3] is right when he states that in Israel a lot of the brackish is used for agriculture and industry and that the desalination of this water does not add to the total potable water supply (see also Table 1). The potential to increase the capacity of brackish water desalination plants is limited, because there are no significant sources of brackish water located within the vicinity of large population centers or the NWC. The potential of additional sources of desalinated brackish water to the water supply in Israel is expected to be limited to 50 million $\mathrm{m}^{3}$ [3]. The treatment of wastewater, either by desalination or by other methods is promising, but similar to brackish water, desalinated wastewater, which is currently applied in agriculture or industry does not add to the total water supply for domestic purposes. Israel boasts one of the highest percentages of wastewater recycling.
At present, already over $73 \%$ of municipal wastewater is recycled [14]. Other disadvantages of wastewater desalination are that the technology is still under development and that the costs are of the same order as desalinating seawater [38]. Under these circumstances, seawater shows the most potential for increasing the water supply in Israel, both in the short as well as in the long run.

In the coming decade, the Israeli government aims to greatly increase the contribution of desalinated water to the national water supply. The IWC expects desalination to account for 315 million $\mathrm{m}^{3}$ of potable water in 2010. By 2020, this figure is expected to double, reaching 650 million $\mathrm{m}^{3}$ of desalinated water annually. This increase in desalination capacity is planned to be realized through the construction of large scale SWRO plants and the expansion of the capacity of existing plants [2].

By the end of 2009, an additional 100 million $\mathrm{m}^{3} / \mathrm{yr}$ $\mathrm{RO}$ plant is expected to come on line in Hadera. A 45 million $\mathrm{m}^{3} / \mathrm{yr}$ desalination plant to be located in Ahsdod is in the pre-tendering phase, as is the expansion of the capacity of already existing plants by 40 million $\mathrm{m}^{3}$. The area of Schafdan is expected to see a 100 million $\mathrm{m}^{3} / \mathrm{yr}$ desalination plant by 2015. By then, another 85 million $\mathrm{m}^{3} / \mathrm{yr}$ will be added to already existing desalination plants [2]. Table 6 displays an overview of the projected increase in desalination capacity by 2020 .

\subsection{Desalination by the Dead Sea Canal}

A controversial issue, the construction of a canal to the Dead Sea has been discussed for over a century, since before the creation of the State of Israel. The initial idea by Theodore Herzl was to construct a canal between the Mediterranean Sea and the Dead Sea [39]. This canal is referred to as the Med Sea Dead Sea canal, or the MSDS canal. Since then, many alternatives to the MSDS canal have been considered, most notably the Red Sea Dead Sea canal or the RSDSC, also referred to as the Two Seas Canal. The arguments about which of the two is best are as numerous as they are complicated and involve environmental as well as economical 
Table 6

Overview of projected desalination plants in Israel and expected desalination capacity 2020

\begin{tabular}{lll}
\hline Name & $\begin{array}{l}\text { Capacity } \\
\text { (million } \\
\left.\mathrm{m}^{3} / \mathrm{yr}\right)\end{array}$ & Status \\
\hline Hadera & 100 & $\begin{array}{c}\text { Expected to come } \\
\text { on-line in 2009 } \\
\text { Pre-tendering phase } \\
\text { Pre-tendering phase }\end{array}$ \\
$\begin{array}{l}\text { Additional capacity } \\
\quad \text { existing plants }\end{array}$ & 45 & $\begin{array}{l}\text { Long term planning } \\
\text { Long term planning }\end{array}$ \\
$\begin{array}{l}\text { Additional capacity } \\
\text { existing plants }\end{array}$ & 100 & By 2020 \\
$\begin{array}{l}\text { Required additional } \\
\text { capacity }\end{array}$ & 150 & 2020 \\
$\begin{array}{l}\text { Long term desalination } \\
\text { capacity }\end{array}$ & 650 & \\
\hline
\end{tabular}

and diplomatic considerations. At this moment, the RSDSC is receiving the most attention, because Israel, the PA and Jordan have agreed to a feasibility study assessing its potential. This project is referred to as the Red-Dead Conveyance Project or RDCP. The World Bank is financing two studies investigating the economical potential, the environmental consequences and the financial aspects of the construction of the RDCP [40].

Besides the restoration of the Dead Sea, its positive effects on the peace process and the production of electricity from hydroelectric energy, the main purpose of the Dead Sea canal is to desalinate water. The RDCP is expected to power a large-scale reverse osmosis plant that can provide water for Israel and its neighboring countries. The current projections are that RDCP will be able to provide up to 850 million $\mathrm{m}^{3}$ of fresh water annually, most of which will go to the West bank and Amman [40]. An alternative to the RDCP is the Dead Sea Power Project (DSPP), which advocates the construction of a MSDS canal. Proponents of the DSPP claim a huge potential for desalinated water providing up to 4,000 million $\mathrm{m}^{3}$ of water annually to Jordan, Israel and the PA.

Both the RDCP and the DSPP have the potential to supply the region with large quantities of desalinated water without relying on conventional fossil fuels. There are, however, several reasons why Israel should continue to develop its own reliable sources of water in the form of renewable energy fueled desalination.

The first reason is the uncertainty as to whether any of the projects will ever be realized. Currently, the Dead Sea canal only exists on paper. Even though studies have been published emphasizing the enormous potential of the project, feasibility studies are still underway and might turn up negative. Besides that, the construction of a project of these dimensions requires the cooperation of many stakeholders, each with different interests. The sensitive situation of the projects regarding the environment can grind the development of the project to a halt [41]. The involvement of environmental organizations and international interest groups may further complicate the situation.

The second reason is that even if the construction of the canal will ever see the green light, the time span associated with its completion is large. Estimates of the time necessary to complete the RDCP vary from 7 to 13 years [40]. Recent estimates by the World Bank indicate a time span of 2 years for the feasibility study and 5 years for the actual completion of the project. Outdated estimates of the Harza group indicate a longer time span of 13 years before the project can become operational. Advocates of the DSPP estimate the planning of the project to take 2 years and the actual construction to require 7 years. This does not include the time necessary for a feasibility study and negotiations between the different parties. For both projects a delay during the construction phase is not unlikely, due to the unstable political circumstances in the region and the far reaching economical and environmental implications of the projects.

\section{The economics of energy for desalination in Israel}

If the IWC wants to increase the capacity of desalinated water in Israel to 650 million $\mathrm{m}^{3}$ annually by 2020 , it needs to commission the additional construction of desalination units with a combined capacity of 400 million $\mathrm{m}^{3} / \mathrm{yr}$. Disregarding cost factors, employing state-of-the-art technology and under perfect circumstances, researchers have demonstrated the possibility of SWRO with a specific energy consumption of $2 \mathrm{kWh} / \mathrm{m}^{3}$ [10]. It is, however, unlikely that new SWRO plants in Israel will attain this efficiency in the short run. A more plausible scenario is that the specific energy consumption for SWRO in Israel will decrease slightly compared to the Ashkelon plant to $3 \mathrm{kWh}$ per $\mathrm{m}^{3}$. This would require an annual amount of energy equivalent to 1,200 GWh. This excludes the amount of energy associated with the construction and the maintenance of the plant. It is most likely that new conventional fuel powered desalination plants will be fueled by the on site generation of electricity from natural gas. Natural gas prices in Israel varied around 3.2 US\$ per MMBtu in 2005 [25] (one MMBtu is one million British thermal units; $1 \mathrm{Btu}$ is equivalent to 1055 Joule). To produce $1200 \mathrm{GWh}$ with an average power plant efficiency of $40 \%$ requires about $3,000 \mathrm{GWh}$ of input or 10.2 million 
MMBtu of natural gas. Assuming natural gas prices to remain constant, this amount of natural gas would cost 32.8 million US\$ annually. This leads to a water cost of $32.8 / 400=0.082 \mathrm{US} \$ / \mathrm{m}^{3}$.

A more accurate prediction about the costs of energy associated with the introduction of an additional desalination capacity of 400 million $\mathrm{m}^{3} / \mathrm{yr}$ can be obtained using data from the Ashkelon plant. From data presented by Dreizin in 2006, it can be inferred that energy prices for the Ashkelon SWRO plant are close to $0.042 \mathrm{US} \$ / \mathrm{kWh}$. We assume that these prices are also valid for the new desalination plant. It is, however, unlikely that the new plant will be able to secure natural gas prices nor electricity prices that are as favorable as for the Ashkelon plant. The cost estimates are therefore on the conservative side. In a paragraph on desalination costs, Sagie et al. presume a grid electricity price of $0.065 \mathrm{US} \$ / \mathrm{kWh}$ for new desalination plants [23]. Multiplying the conventional electricity costs from the Ashkelon plant with 1,200 GWh, gives annual energy costs of around 50.4 million US\$. For the electricity price of Sagie, annual electricity costs would be 78 million US $\$$, and water costs would be $78 / 400$ (Ashkelon capacity; $0.195 \mathrm{US} \$ / \mathrm{m}^{3}$ ).

The previous survey of the renewable energy situation in Israel indicates that the only viable option to power the increased desalination capacity with renewable energy is through solar power. Solar power can be divided in concentrating solar power (CSP) and photovoltaics (PV). Both CSP and PV powered desalination are examples of indirect solar desalination, where solar radiation is converted to electricity, which is used to power the desalination process [42]. Even though the use of PV is expected to grow exponentially during the following years, its use for powering large scale desalination plants in Israel is limited [43]. The energy costs of PV are still too high and the scale of PV systems is still too small for the large energy requirements of the desalination processes $[23,44]$. This claim is backed up by data from the US Department of Energy and pvresources.com, which shows that the largest PV plants have a capacity of $20 \mathrm{MWp}$ and the most efficient PV systems provide energy at the cost of $0.15 \mathrm{US} \$ / \mathrm{kWh}$ $[43,45]$. In a recent paper, El-Sayed claims that PV powered desalination is almost competitive with conventional fuel based desalination. In the same paper, however, he shows that the most advanced PV cell under the most favorable circumstances provides electricity at the cost of $0.108 \mathrm{US} \$ / \mathrm{kWh}$, which is more than twice the price of regular electricity [46].

According to an extensive study conducted by Greenpeace, the European Solar Thermal Power Industry Association (ESTIA) and the International Energy Agency, Concentrating Solar Power (CSP) is the most promising renewable energy technology for countries with a high solar radiation, such as Israel. The most suitable CSP technology for Israel is the parabolic trough, because it is commercially available, has the lowest land requirements, can be equipped with storage facilities to guarantee continuous operation and can be hybridized with gas power plants to decrease energy costs. In the past, large cost reductions have brought down electricity costs from parabolic troughs to 1517 US\$ per kWh. According to the same study, technological advancements and the mass production of solar troughs, brought forward by the anticipated CSP revival in the USA, will reduce electricity costs to 0.09 US\$ / $\mathrm{kWh}$ in 10 years. In a recent report on the potential of CSP, Shinnar and Citro confirm that cost savings are to be expected [44]. Hybrid systems, combining CSP and gas fueled power plants, also dubbed Integrated Solar Combined Cycle (ICCS) systems, can provide electricity costs ranging from 0.09 to $0.10 \mathrm{US} \$ / \mathrm{kWh}$ to 0.075 US\$ / $\mathrm{kWh}$ in the long run [47]. For Israel, where labor is relatively cheap and the CSP industry is advancing rapidly, costs could be even more favorable. Sagie claims that costs for the first hybrid natural gas CSP plant in Israel, with a solar fraction of 40 to $50 \%$, will lie between 0.07 and $0.08 \mathrm{US} \$ / \mathrm{kWh}$, possible even dropping to $0.065 \mathrm{US} \$ / \mathrm{kWh}$ [25]. In that case, annual energy costs would be between 96 and 78 million US\$.

Current plans by the Israel Electric Company to produce a 100 MWe CSP plant are still deliberated upon. The initial costs of electricity generated by the plant are close to $0.09 \mathrm{US} \$ / \mathrm{kWh}$. Later plans to expand the plant to $500 \mathrm{MWe}$ can bring the costs down to 0.07 US\$/kWh [33]. Although land requirements for solar energy and CSP in particular are high and hence constitute an important part of the capital costs, large areas of inexpensive desert land make this less of an issue in Israel and its neighbors [48]. When comparing the costs of energy from CSP with the costs of energy for the Ashkelon plant, total energy costs would initially more than double when using CSP. However, the lifetime of a desalination plant is rarely shorter than 25 years. It is therefore important to look at long-term projections for energy costs when calculating the most suitable energy system for a desalination plant [19]. This is why the large cost reductions for CSP in the next ten years might make renewable energy economically feasible for desalination purposes on the long run. Notwithstanding the large cost reductions, the long term energy costs for CSP are still almost $0.03 \mathrm{US} \$ / \mathrm{kWh}$ more expensive compared to current prices of fossil fuels, which would translate to 36 million US\$ annually. This is partially due to the fact that many negative externalities of the use of fossil fuels, such as 
Table 7

Water prices in US $\$ \mathrm{~m}^{3}$ for Ashkelon, Palmachim and Hadera, at date of contract and December 2006 and the relative differences (in \%) [2]

\begin{tabular}{|c|c|c|c|c|c|c|c|c|c|}
\hline \multirow[t]{2}{*}{ Plant } & \multicolumn{3}{|l|}{ Ashkelon } & \multicolumn{3}{|c|}{ Palmachim } & \multicolumn{3}{|l|}{ Hadera } \\
\hline & Apr. 2002 & Dec. 2006 & $\%$ & Oct. 2002 & Dec. 2006 & $\%$ & Nov. 2006 & Dec. 2006 & $\%$ \\
\hline Total price & 0.51 & 0.66 & +29 & 0.56 & 0.74 & +31 & 0.60 & 0.61 & +2.4 \\
\hline
\end{tabular}

air pollution or climate change, are not incorporated in the price of electricity generated by their combustion. If, for instance, the combustion of fossil fuels was to be accompanied by adequate $\mathrm{CO}_{2}$ disposal, the comparison between the two prices would be more balanced $[44,47]$.

In the long run, however, this price difference is expected to decrease. Due to increasing scarcity, the energy prices of fossil fuels are expected to rise during the next decades [6]. According to the International Energy Outlook 2007 by the USA Energy Information Administration, fossil fuel prices are expected to rise until 2030 [48]. A steady increase in the price of fossil fuels entails higher costs for electricity generation from fossil fuels in the long run. Empirical data illustrating the magnitude of the effects of energy costs on water prices is presented in Table 7 . It shows the prices for water at the time of the signing of the contract as compared to the prices at the end of 2006 and the change in percentages between both prices. According to Dreizin et al [2], the large differences in prices for water in Ashkelon and Palmachim are mainly due to "large escalations in energy costs over the past two years", thereby supporting the argument that increases in energy prices for fossil fuels reduce the competitiveness of conventional fuel based desalination plants.

Electricity generated from renewable energy is usually sold for a contracted fixed price. As is the case with electricity for desalination plants in Israel, electricity prices from fossil fuels are often linked to volatile fossil fuel price indexes. This makes electricity from fossil fuels a more risky investment option. In Israel, desalination is usually powered by the on site electricity generation through the combustion of natural gas. Over the last 10 years, natural gas prices have increased fivefold [44]. According to Bolinger et al, in order to account for the risk of price fluctuations for natural gas, hedged natural gas prices should be used, which present a price increase of 0.004-0.006 US\$/kWh [49].

\subsection{Direct solar desalination}

Direct solar desalination is a form of desalination that uses solar energy directly to desalinate water. Solar radiation is captured by the facility and converted to heat, which is used to evaporate water, all in the same system. When the water condenses, it is captured and fresh water is obtained. This process omits the electricity generation step, which in theory increases the efficiency of the system as a whole. Experience with direct solar desalination is minimal and it exists in practice only in the form of pilot plants and small scale facilities for remote regions [8]. Direct solar desalination has higher area requirements and a lower productivity than indirect solar desalination systems [42]. Khawaji et al. [8] mention an area requirement of 25 hectares for the daily production of $1,000 \mathrm{~m}^{3}$ of fresh water. This translates to $0.68 \mathrm{~km}^{2}$ per million $\mathrm{m}^{3} / \mathrm{yr}$ or $273.97 \mathrm{~km}^{2}$ to meet the projected capacity increase of 400 million $\mathrm{m}^{3} / \mathrm{yr}$. These high land requirements combined with the high costs associated with direct solar distillation, around $3 \mathrm{US} \$ / \mathrm{m}^{3}$, make it unsuitable for introduction on a large scale in Israel [46].

\section{Recommendations and policy measures}

In the short run, environmental premiums, either from the Israeli government, such as feed in tariffs, or from the international community, such as revenues from CDM projects, can make renewable energy fueled desalination economically feasible and facilitate its introduction in the Israeli water market [25]. Although this may change during the second commitment period of the Kyoto Protocol, Israel is currently considered a developing country, or Annex II country [50]. Until this changes, certified reduction credits (CERs) can be obtained from Clean Development Mechanism (CDM) projects in Israel and sold to developed or Annex I countries. This can increase the economical feasibility of clean energy projects, such as the use of CSP to power desalination plants. If further studies indicate that large-scale CSP plants are not yet economically feasible in Israel without financial support, this satisfies the additionality requirement and the plant can qualify as a CDM project. The European Climate Exchange (ECX) reports the price of CERs to pass 20 Euro per tonne of $\mathrm{CO}_{2}$ in June 2008 [51]. With the exchange rate on the 20th of June 2008 being roughly 1.55 US\$ to the Euro, 
this translates to 31 US\$ per tonne of $\mathrm{CO}_{2}$. It is assumed that each MWh of CSP capacity installed prevents the emission of 600 kilograms of $\mathrm{CO}_{2}$, based on national emission data from the current energy mix [33]. If CERs are sold at current prices, this would provide an economical benefit of 0.0186 Euro/kWh. Moreover, if Israel becomes a part of the Annex I countries in 2013, early investments in emission reductions will pay off in the long run and emission reductions can be traded with other Annex I countries.

When aiming to expand the national desalination capacity in the next decade, the government should consider the use of renewable energy as a source of power for new desalination plants and increasing the overall energy capacity of the country. When considering renewable energy for desalination, the government should take into account the wide range of indirect benefits of renewable energy fueled desalination. The availability of knowledge, state-of-the-art technology and a well-educated workforce combined with a stable economic and political climate, provide the opportunity for Israel to become a market leader in the field of renewable energy and in particular solar energy [35]. By focusing on renewable energy, the government can stimulate economic activity in this sector and play an important role in realizing this potential. The results are economic growth, additional employment and indirectly, also environmental benefits. The Ministry of Environment should realize that natural gas might be environmentally beneficial compared to coal or oil, but is in essence still finite and polluting. By introducing renewable energy in the energy market in Israel, the country is diversifying its energy sector. This will reduce the country's dependency on imported fossil fuels and avoid the risks of escalating energy prices due to peak oil. An added benefit is a decreased contribution to climate change. By fueling desalination with renewable energy, the price of water remains stable, which is vital for the wellbeing of the country. An increased share in renewable energy will also curb rising levels of air pollution in large population centers all over the country [47].

Not only Israel, but the whole region suffers from severe water shortages. Israel shares many of its water resources with its neighboring countries, the Palestinian Authority, Jordan, Syria and Lebanon. In the past this has led to political tension, which can be an obstruction for the already fragile peace process. Eventually, Israel can use its experience with renewable energy fueled desalination to help its neighbors to develop a sustainable water system of their own. Cooperation in the field of water resources is essential for the region and the benefits of a sustainable water system can provide a solid basis for the peace negotiations.

\section{Conclusion}

A large increase of the seawater desalination capacity in Israel is inevitable to guarantee a reliable supply of affordable fresh water in the future. The environmental aspects of desalination plants should be carefully evaluated using Environmental Impact Assessments. In order to meet the large energy demand of additional desalination facilities, Israel should deliberate the use of renewable energy. The most suitable form of renewable energy for desalination in Israel is concentrating solar power. When taking into account the long lifetime of desalination plants and the expected price increase of fossil fuels, a costlier investment in CSP is a more sensible alternative than a further expansion of the fossil fuel sector. The negative externalities of the use of fossil fuels, such as air pollution and the contribution to climate change, provide an additional motivation for renewable energy. Additional benefits of the use of CSP include a more independent and stable energy sector and the possibility of becoming a market leader in the field of solar energy. The government should consider these factors and facilitate the development of renewable energy for desalination by improving its renewable energy policy. Financial incentives can make CSP for desalination economically feasible on the short run, and ascertain long lasting economic and social benefits for the whole country.

\section{Acknowledgments}

We would like to express our gratitude to everybody that contributed to the writing of this article, in particular the five experts that were willing to divert their time to introduce us to the Israeli water market and provide us with the knowledge and background information that was invaluable for this research. In alphabetical order: Avraham Israeli, A.R. Israeli Technologies Ltd., Avraham Tenne, Water Authority Israel, Avi Ramot, Water Commission, Ardom Eilot Regional Enterprises, Dan Zaslavsky, Technion - Israel Institute of Technology, Nehemiah Hassid, Ben-Gurion University of the Negev. Further, MH would like to thank the Arava Institute for Environmental Studies, for their hospitality and aid during the research process in Israel.

\section{References}

[1] J.L. Chenoweth and W. Wehrmeyer, Scenario Development for 2050 for the Israeli/Palestinian Water Sector, Popul. Environ., 27 (2006) 245-261.

[2] Y. Dreizin, A. Tenne and D. Hoffman, Integrating large scale seawater desalination plants within Israel's water supply system, Desalination, 220 (2008) 132-149. 
[3] Y. Dreizin, Ashkelon seawater desalination project - off-taker's self costs, supplied water costs, total costs and benefits, Desalination, 190 (2006) 104-116.

[4] D. Hoffman, Y. Dreizin and G. Kronenberg, III. Case study: the need for, and costs of, seawater desalination in Israel, Filtrat. Separ., 42 (3) (2005) 20-21.

[5] A. Ben-Zvi, E. Dlayahu, M. Gottesmann and A. Passal, Evolution of the 1990-1991 Water Crisis in Israel, Water Int., 23 (2) (1998) 67-74.

[6] L.K. Hamdan, M. Zarei, R.R. Chianelli and E. Gardner, Sustainable water and energy in Gaza Strip, Renew. Energ., 33 (2008), 1137-1146.

[7] I.C. Karagiannis and P.G. Soldatos, Water desalination cost literature: review and assessment, Desalination, 223 (2008) 448456.

[8] A.D. Khawaji, I.K. Kutubkhanah and J.-M. Wie, Advances in seawater desalination technologies, Desalination, 221 (2008) 47-69.

[9] A. Israeli, Personal communication, 2008.

[10] C. Fritzmann, J. Löwenberg, T. Wintgens and T. Melin, State-ofthe-art of reverse osmosis desalination, Desalination, 216 (2007) $1-76$.

[11] Y. Zhou and R. Tol, Evaluating the costs of desalination and water transport, Water Resour. Res., 41 (2005) W03003.

[12] S. Lattemann and T. Höpner, Environmental impact and impact assessment of seawater desalination, Desalination, 220 (2008) 1-15.

[13] I. Safrai and A. Zask, Reverse osmosis desalination plants - marine environmentalist regulator point of view, Desalination, 220 (2008) $72-84$

[14] A. Tal, seeking sustainability: Israel's evolving water management strategy, Science, 313 (2006) 1081-1084.

[15] R. Einav and F. Lokiec, Environmental aspects of a desalination plant in Ashkelon. Desalination, 156 (2003) 79-85.

[16] Adam Teva V'Din - Israel Union of Environmental Defense http://www.adamteva.org.il/?CategoryID=388 - June 2008.

[17] R. Clayton, Desalination for Water Supply, Foundation for Water Research (2006) Report FR/R0013.

[18] K.Z. Al-Subaie, Precise way to select a desalination technology, Desalination, 206 (2007) 29-35.

[19] G. Raluy, L. Serra and J. Uche, Life cycle assessment of MSF MED and RO desalination technologies, Energy 31 (2006) 2361-2372.

[20] R. Borsani and S. Rebagliati, Fundamentals and costing of MSF desalination plants and comparison with other technologies, Desalination, 182 (2005) 29-37.

[21] S.A. Kalogirou, Seawater desalination using renewable energy sources, Progr. Energ Combust. Sci., 31 (2005) 242-281.

[22] Ministry of the Environment, Israel's Experience in Sustainable Energy, January 2006.

[23] D. Sagie, E. Feinerman and E. Aharoni, Potential of solar desalination in Israel and in its close vicinity, Desalination, 139 (2001) 21-33.

[24] T Ackermann, Historical Development and Current Status of Wind Power, in: T. Ackermann, ed., Wind Power in Power Systems, Wiley, Chichester, United Kingdom, 2005, pp. 5-24.

[25] D. Sagie, Feasibility Study of 100 MWe Solar Power Plant, Proceedings of the 2005 Solar World Congress, D.Y. Goswami, S. Vijayaragharven, R. Campbell-Howe, eds., International Solar Energy Society (ISES) (2005).

[26] L. Koifman, Geothermal resources in Israel, Desalination, 40 (1982) 133-134.
[27] Y. Greitzer and D. Levitte, Geothermal update from Israel 1999 Proceedings World Geothermal Congress, 2000.

[28] D. Levitte and Y. Greitzer, Geothermal update report for Israel 2005. Proceedings World Geothermal Congress, 2005.

[29] J.W. Lund, D. H. Freeston and T. L. Boyd, Direct application of geothermal energy: 2005 Worldwide review, Geothermics, 34 (2005) 691-727.

[30] D\&A High-tech Information, Renewable energy in Israel, September 2006

[31] Israel Energy Forum - http://www.energia.org.il/en.

[32] Paths to Sustainability Coalition, Non-Sustainable Development in Israel: A Position-Paper of "Paths to Sustainability" Coalition of Israeli Environmental and Social NGOs, Heinrich Böll Foundation, April 2007.

[33] G. Brakmann, R. Aringhoff, M. Geyer and S. Teske, Concentrated solar thermal power - now!, Greenpeace, Amsterdam, the Netherlands, September 2005.

[34] Mekorot Water Company, Desalination, Water Technologies and Environmental Control (WATEC-2007), Tel Aviv, Israel, October 30, November 1, 2007.

[35] R. Semiat, Desalination education capacity in Israel, Desalination, 141 (2001) 191-198.

[36] P. Glueckstern and M. Priel, Advanced concept of large seawater desalination systems for Israel, Desalination, 119 (1998) 33-45.

[37] M. Priel, P. Glueckstern and N. Perlov, Seawater vs. different raw-water sources desalination, Desalination, 199 (2006) 317-318.

[38] P. Glueckstern, M. Priel, E. Gelman and N. Perlov, Wastewater desalination in Israel, Desalination, 222 (2008) 151-164.

[39] N. Sokolow, Book 4, chapter 3 (in Hebrew).

[40] M. Beyth, The Red Sea and the Mediterranean-Dead Sea canal project, Desalination, 214 (2007) 365-371.

[41] A. Ramot, Personal communication, 2008.

[42] H.M. Qiblawey and F. Banat, Solar thermal desalination technologies, Desalination, 220 (2008) 633-644, January 2007.

[43] U.S. Department of Energy - Energy Efficiency and Renewable Energy, Solar Energy Technologies Program, Multi-Year Program Plan 2007-2011, January 2006.

[44] R. Shinnar and F. Citro, Solar thermal energy: The forgotten energy source, Technology in Society, 29 (2007) 261-270.

[45] D. Lenardic, Large-Scale Photovoltaic Power Plants, Cumulative and Annual Installed Power Output Capacity, Annual Report 2007 - Revised Edition April 2008, Report PVresources.com.

[46] Y.M. El-Sayed, The rising potential of competitive solar desalination, Desalination, 216 (2007) 314-324.

[47] A. Mor, S. Seroussi and M. Ainspan, The GREENPEACE Report For Solar Energy in Israel, Economic and Social Impacts from Large Scale Utilization of Solar Energy in Israel, July 2005.

[48] Energy information Administration, International Energy Outlook 2007, http://www.eia.doe.gov/oiaf/ieo/index.html.

[49] M. Bolinger, R. Wiser and W. Goloveet, Accounting for fuel price risk when comparing renewable to gas-fired generation: the role of forward natural gas prices, Energ. Pol., 34 (2006) 706-720.

[50] Entering the Carbon Market: CDM Projects in Israel, Israel Environment Bulletin, 31 (2006) 16-17.

[51] European Climate Exchange, http://www.ecx.eu/default_flash .asp, 20 June 2008. 